\title{
Tandem immunoaffinity purification of protein complexes from Caenorhabditis elegans
}

\author{
Jolanta Polanowska, Julie S. Martin, Rhoda Fisher, Tina Scopa, \\ Ian Rae, and Simon J. Boulton \\ Cancer Research UK, The London Research Institute, South Mimms, UK \\ BioTechniques 36:778-782 (May 2004)
}

Multiprotein complexes are the functional units of many cellular processes. Defining the components of these complexes, how they associate, and their intrinsic biochemical activities provides a wealth of information about the context in which proteins operate (1-5). The nematode Caenorhabditis elegans is a powerful organism for genetically defining cellular pathways, but how the proteins operate biochemically within such pathways has not been explored significantly due to the absence of robust systems for biochemical studies. Here we describe the first method for tandem immunoaffinity purification of native protein complexes from C. elegans that can be applied to any nematode protein of interest.

We have constructed pSB_GW:: TAG, a Gateway ${ }^{\circledR}$ destination vector that can be used to generate transgenic animals that express any gene of interest (G.O.I.) fused at the $3^{\prime}$ end to HA $8 \times$ His_TEV_Myc epitopes, enabling associated protein complexes to be purified from whole worm extracts by tandem immunoaffinity chromatography (Figure 1A). Using Gateway-specific primers, with the open reading frame of the $3^{\prime}$ primer kept open to enable readthrough into the epitope tags, the promoter and coding region of a G.O.I. are PCR amplified from cosmid DNA (6). The PCR product is BP cloned into the Gateway entry vector, sequenced, and then transferred by LR cloning into pSB_GW::TAG (Figure 1A and www.BioTechniques.com/May 2004 PolanowskaSupplementary.html and Reference 6). The pSB_G.O.I::TAG is then delivered into unc-119(ed3) mutants by microparticle bombardment (supplementary information and Reference 7). Stable transgenic animals iso- lated by complementation are then tested for transgene expression by Western blot analysis using antibodies against either the hemagglutinin (HA) epitope (MAb12CA5), 8×His, or the Myc epitope (MAb9E10).

To generate sufficient starting material for purification purposes, we have optimized large-scale production of nematode transgenic lines in BioFlo $5000^{\circledR}$ fermenters [New Brunswick Scientific (UK) Ltd., St. Albans, Hertfordshire, UK]. The transgenic line is grown at $20^{\circ} \mathrm{C}$ in liquid culture $(10 \mathrm{mg} / \mathrm{L} \mathrm{S}$ basal, nystatin, $50 \mathrm{mg} / \mathrm{L}$ streptomycin, and $20 \mathrm{~g} / \mathrm{L}$ of Escherichia coli HB101) on a shaking platform ( $250 \mathrm{rpm})$ until $5 \mathrm{~L}$ of dense worm culture are generated (8). This is poured directly into a BioFlo 5000 fermenter, containing 60 L of S-basal supplemented with antibiotics and HB101 as described above. To obtain a high density of live worms after 7-9 days growth in the fermenter, parameters such as temperature $\left(22^{\circ} \mathrm{C}\right)$, agitation $(100 \mathrm{rpm})$, oxygenation $(20 \mathrm{~L} /$ $\mathrm{min}$ ), and $\mathrm{pH}$ (6.0) are kept constant to ensure optimal C. elegans growth. The worms are then harvested using a Cepa continuous centrifuge [Model 241; New Brunswick Scientific (UK) Ltd.], washed twice in cold $0.1 \mathrm{M} \mathrm{NaCl}$, and subjected to centrifugation at $2300 \times$ $g$ in $30 \%$ sucrose at $4{ }^{\circ} \mathrm{C}$ for $5 \mathrm{~min}$ to remove residual bacteria and dead worms (Figure 1B). The live worms are collected from the top of the sucrose solution, washed a third time in cold $0.1 \mathrm{M} \mathrm{NaCl}$, and then resuspended in twice the worm pellet volume of CSK lysis buffer [100 mM PIPES, pH 6.0, $100 \mathrm{mM} \mathrm{NaCl}, 3 \mathrm{mM} \mathrm{MgCl}, 1 \mathrm{mM}$ EGTA, $1 \mathrm{mM}$ dithiothreitol (DTT), 1 $\mathrm{mM}$ phenylmethylsulfonyl fluoride (PMSF), $0.3 \mathrm{M}$ sucrose, $0.5 \%$ Triton $^{\circledR}$ $\mathrm{X}-100$, Complete Protease Inhibitor Tablets (Roche Applied Science, Indianapolis, IN, USA), and phosphatase inhibitors $(2 \mathrm{mM} \beta$-glycerophosphate, $5 \mathrm{mM} \mathrm{NaF}, 1 \mathrm{mM} \mathrm{Na} \mathrm{VO}_{4}, 0.1 \mu \mathrm{M}$ okadaic acid)]. The mixture can then be frozen down in 50-mL aliquots on dry ice and stored at $-80^{\circ} \mathrm{C}$. From a $60-\mathrm{L}$ fermenter run, the final yield of live worms averages $640 \mathrm{~g} \pm 70(n=7)$.

The weight of the worms required for purifying a given protein complex in sufficient amounts for protein identification by mass spectrometry is dependent on the level of expression from the genes' promoter and must be determined for each transgene (see supplementary information). To generate whole worm extracts, a single freeze/ thaw cycle is performed before the suspension is dounced 6 times in a homogenizer (Borosilicate homogenizer; Fisher Scientific, Loughborough, UK). The mixture is clarified by centrifugation at $3500 \times g$, the soluble supernatant fraction is collected, and the pellet is resuspended in half the pellet volume of CSK. To extract the chromatin fraction from the pellet, micrococcal nuclease (Roche Applied Science) is added to a final concentration of $3 \mathrm{U} / \mu \mathrm{L}$ and incubated at $20^{\circ} \mathrm{C}$ with gentle shaking for $30 \mathrm{~min}$ before the reaction is stopped

\footnotetext{
Figure 1. Protein complex purification from Caenorhabditis elegans. (A) Gateway recombination is used to clone the promoter and coding region $(\mathrm{P}+\mathrm{C})$ for a gene of interest (G.O.I.) into p221 using the BP reaction and from p221 into pSB_GW::TAG using the LR reaction (6). An example of this is shown on the right, in which universal primers have been used to PCR amplify the promoter and coding region for Y41E3.9 from pSB_Y41E3.9::TAG. (B) Microparticle bombardment is used to integrate the construct into unc-119(ed3) mutants at low copy to generate a transgenic line expressing the protein of interest (P.O.I.) fused to C-terminal epitope tags. The transgenic line is grown to high density in a BioFlo 5000 fermenter, harvested, and extracts are generated for purification purposes. (C). Tandem immunoaffinity chromatography over protein A-MAb12CA5, and then protein A-MAb9E10 is used to purify the P.O.I.-associated protein complex before complex components are identified by mass spectrometry. An example is shown on the right of a silver-stained 4\%-12\% gradient gel that compares the mock purification after (1.) hemagglutinin (HA) and (2.) HA + Myc to the (3.) Y41E3.9-associated protein complex after HA + MYC immunoaffinity. His, histidine; TEV, tobacco etch virus; E. coli, Escherichia coli; MNase, micrococcal nuclease; S, soluble supernatant fraction; $\mathrm{C}$, chromatin fraction; M, molecular weight marker (Invitrogen).
} 


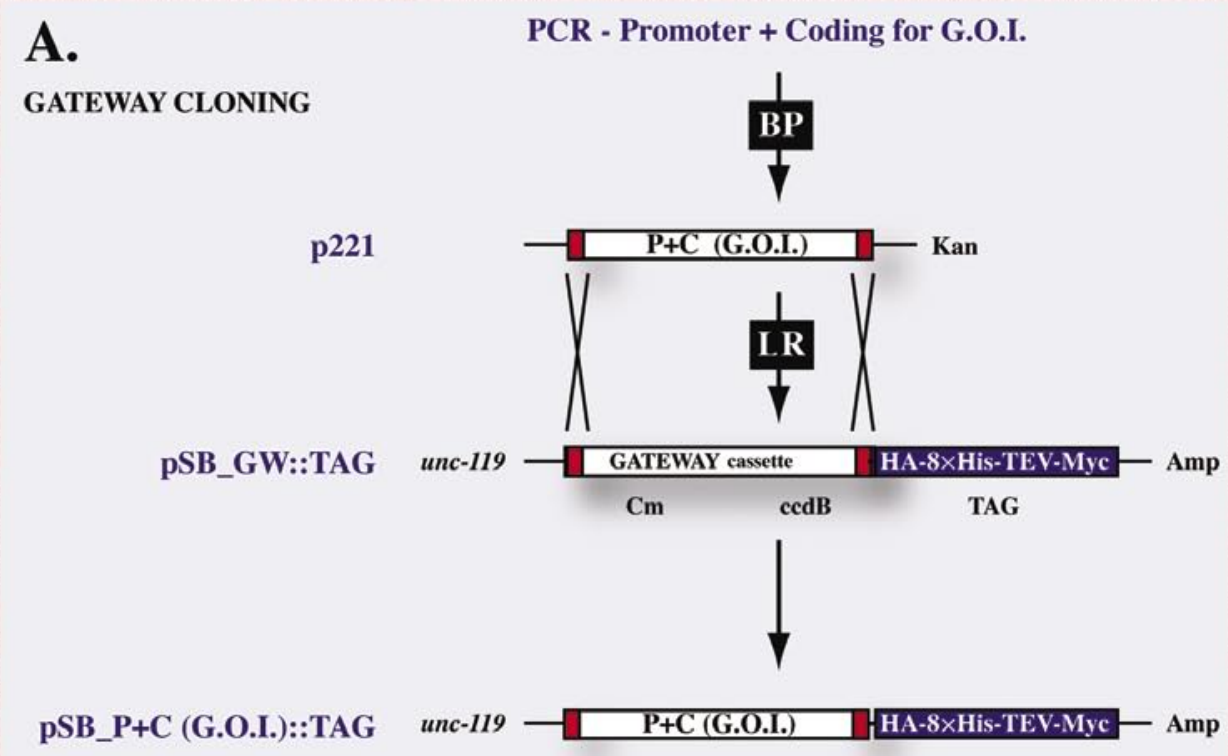

\section{Example}

$\mathrm{P}+\mathrm{C}$ [Y41E3.9]

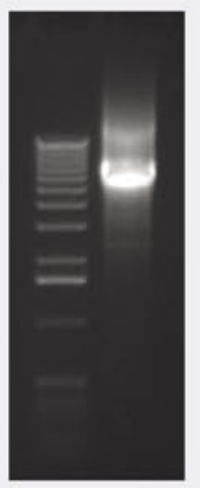

Microparticle

bombardment

OF TRANSGENIC LINE

Transgenic line

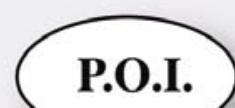

HA-8 $\times$ His-TEV-Myc

HB101 E. coli

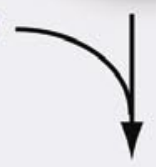

BioFlo 5000 fermenter

Harvest by continuous centrifugation

C.

PROTEIN COMPLEX PURIFICATION

Tandem immunoaffinity chromatography

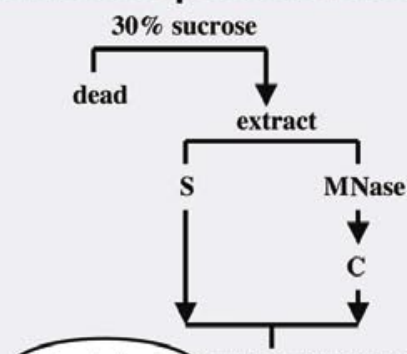

Protein A
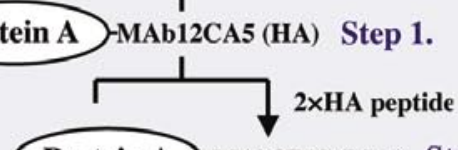

Protein A -MAb9E10 (Myc) Step 2.

TEV
1. Mock HA

2. Mock HA + Myc

3. Y41E3.9 HA + Myc

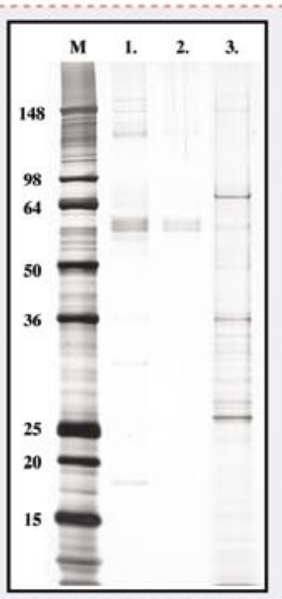

P.O.I. -associated protein complex

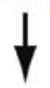

Mass spectrometry of complex components 
by the addition of $5 \mathrm{mM}$ EDTA and 5 mM EGTA. High-speed centrifugation at $15,000 \times g$ is used to collection the chromatin fraction supernatant.

To prepare MAb12CA5 (HA)- and MAb9E10 (Myc)-coupled protein A beads, $1 \mathrm{~mL}$ of Sepharose ${ }^{\circledR}$ Protein A Beads (Amersham Biosciences, Piscataway, NJ, USA) is incubated at $20^{\circ} \mathrm{C}$ with mouse ascite ( $2 \mathrm{mg}$ of protein) and washed with 10 volumes of $0.2 \mathrm{M}$ sodium borate, $\mathrm{pH}$ 9.0. Antibody bead coupling is performed at $20^{\circ} \mathrm{C}$ for $30 \mathrm{~min}$ by the addition of $2 \mathrm{mM}$ dimethylpimelimidate dihydrochloride (Sigma, St. Louis, MO, USA) and stopped by washing with 5 volumes of $0.1 \mathrm{M}$ Tris- $\mathrm{HCl}$, $\mathrm{pH} 8.0$, and 10 volumes of phosphatebuffered saline (PBS). The coupled beads are stored at $4{ }^{\circ} \mathrm{C}$ in two volumes of PBS in $0.5 \%$ azide. Prior to purification, the beads are washed in B0.1 buffer (50 mM Tris- $\mathrm{HCl}, \mathrm{pH} 7.3,0.1 \mathrm{M} \mathrm{KCl}, 1$ mM EDTA, and 10\% glycerol).

The first immunoaffinity step is done by batch absorption at $4^{\circ} \mathrm{C}$ for 6 h with $60 \mu \mathrm{L}$ of HA-coupled protein A beads for each milliliter of extract (Figure $1 C$ ). Beads are then transferred to a Poly-Prep ${ }^{\circledR}$ column (Bio-Rad Laboratories, Hercules, CA, USA) and washed
3 times with 5 volumes of B0.1 buffer (supplemented with $1 \mathrm{mM}$ DTT, $1 \mathrm{mM}$ PMSF, $2 \mathrm{mM} \beta$-glycerophosphate, 5 $\mathrm{mM} \mathrm{NaF}, 1 \mathrm{mM} \mathrm{Na} \mathrm{VO}_{4}, 1 \mu \mathrm{M}$ okadaic acid, and complete protease inhibitor tablets). To elute the bound complex, the beads are resuspended in one volume of B0.1 buffer containing $5 \mu \mathrm{g} / \mathrm{mL}$ of double HA peptide and incubated at $4^{\circ} \mathrm{C}$ for $2 \mathrm{~h}$.

Using the same conditions as described above, the HA eluate is then subjected to a second immunoaffinity step using Myc-coupled protein A beads (Figure 1C). Elution from Myc beads was found to be inefficient using Myc peptide so recombinant tobacco etch virus (TEV) protease is used to cleave off the Myc epitope. The cleavage reaction is performed at $20^{\circ} \mathrm{C}$ for $4 \mathrm{~h}$ at a concentration of $1 \mu \mathrm{L}$ TEV per $50 \mu \mathrm{L}$ of HA eluate. The HA-Myc eluate is then resolved on $\mathrm{NuPAGE}^{\circledR} 4 \%-12 \%$ gels (Invitrogen, La Jolla, CA, USA) and stained with either Coomassie ${ }^{\circledR}$ stain or with SilverQuest ${ }^{\mathrm{TM}}$ silver stain (Invitrogen). Bands are then excised and prepared for mass spectrometry analysis as previously described (9). Mass spectrometry analysis is done using an Ultraflex ${ }^{\mathrm{TM}}$ matrix-assisted laser desoption ionization-time of flight (MALDI-TOF) instrument (Bruker Daltonics, Billerica, MA, USA). For protein identification, peak masses are subjected to database searches using the facilities at PepMAPPER and MASCOT (http://wolf.bms.umist. ac.uk/mapper/ and http://www.matrixscience.com/, respectively). Protein complexes identified in this manner have few contaminants because mock purifications from extracts made from an untagged $C$. elegans strain gave only two bands, one of which was identified by mass spectrometry as HSP-70 (C12C8.1; data not shown). The analysis of such complexes in $C$. elegans, when combined with forward and reverse genetic approaches, is likely to accelerate our understanding of many cellular pathways.

\section{ACKNOWLEDGMENTS}

We thank E. Randel Hofmann and Michael Hengartner for the pRH21 used to generate $p S B \_G W:: T A G$. We are grateful to the $\mathrm{C}$. elegans Genetics Centre for providing strains. This work was funded by Cancer Research UK. J.P. and J.S.M. contributed equally to this work.

\section{REFERENCES}

1.Rigaut, G., A. Shevchenko, B. Rutz, M. Wilm, M. Mann, and B. Seraphin. 1999. A generic protein purification method for protein complex characterization and proteome exploration. Nat. Biotechnol. 17:1030-1032.

2.Deshaies, R.J., J.H. Seol, W.H. McDonald, G. Cope, S. Lyapina, A. Shevchenko, R. Verma, and J.R. Yates, 3rd. 2002. Charting the protein complexome in yeast by mass spectrometry. Mol. Cell Proteomics 1:3-10.

3.Gavin, A.C., M. Bosche, R. Krause, P. Grandi, M. Marzioch, A. Bauer, J. Schultz, J.M. Rick, et al. 2002. Functional organization of the yeast proteome by systematic analysis of protein complexes. Nature 415:141-147.

4.Ho, Y., A. Gruhler, A. Heilbut, G.D. Bader, L. Moore, S.L. Adams, A. Millar, P. Taylor, et al. 2002. Systematic identification of protein complexes in Saccharomyces cerevisiae by mass spectrometry. Nature 415:180-183.

5.Shevchenko, A., D. Schaft, A. Roguev, W.W. Pijnappel, and A.F. Stewart. 2002. Deciphering protein complexes and protein interaction networks by tandem affinity purification and mass spectrometry: analytical perspective. Mol. Cell Proteomics 1:204-212.

6.Walhout, A.J., G.F. Temple, M.A. Brasch, J.L. Hartley, M.A. Lorson, S. van den Heuvel, and M. Vidal. 2000. GATEWAY recombinational cloning: application to the cloning of large numbers of open reading frames or ORFeomes. Methods Enzymol. 328:575-592.

7.Praitis, V., E. Casey, D. Collar, and J. Austin. 2001. Creation of low-copy integrated transgenic lines in Caenorhabditis elegans. Genetics 157:1217-1226.

8.Brenner, S. 1974. The genetics of Caenorhabditis elegans. Genetics 77:71-94.

9.Shevchenko, A., M. Wilm, O. Vorm, and M. Mann. 1996. Mass spectrometric sequencing of proteins silver-stained polyacrylamide gels. Anal. Chem. 68:850-858.

Received 28 January 2004; accepted 2 March 2004.

Address correspondence to Simon J. Boulton, DNA Damage Response Laboratory, Cancer Research UK, The London Research Institute, Clare Hall Laboratories, South Mimms, EN6 3LD, UK. e-mail: simon.boulton@cancer.org.uk 